\title{
APRENDIENDO CON EL CUERPO. ETNOGRAFÍA SOBRE BOXEO EN LA CIUDAD DE BUENOS AIRES*
}

\author{
Verónica Moreira \\ veromoreira175@gmail.com \\ Consejo Nacional de Investigaciones Científicas y Técnicas \\ (CONICET), Argentina
}

\section{RESUMEN}

El artículo pretende problematizar, por un lado, la relación que se establece procesualmente entre la mente y el cuerpo en el aprendizaje de la técnica corporal del boxeo. Esto es, cómo los alumnos introducen, incorporan, encarnan los gestos y movimientos deportivos apropiados del pugilismo. Por otro lado, el objetivo es conocer cuáles son los significados del dolor para aquéllos que practican. Los datos surgen de un trabajo de campo realizado en dos clubes de la ciudad de Buenos Aires, en el marco del cual se emplean las dos técnicas principales: la observación participante y la entrevista.

Palabras Clave: cuerpo, boxeo, aprendizaje, dolor.

\section{LEARNING WITH THE BODY. ETHNOGRAPHY ABOUT BOXING \\ IN THE CITY OF BUENOS AIRES}

\section{Abstract}

The article tries to problematize, on the one hand, the relationship that is processively established between the mind and the body in the learning of the boxing body technique. That is, how pupils introduce, incorporate, embody the appropriate sporting gestures and movements of boxing. On the other hand, the goal is to know what the meanings of pain are for those who practice. The data arise from a field work carried out in two clubs in the city of Buenos Aires, using two main techniques: participant observation and interview.

KEYwORDs: body, boxing, learning, pain. 


\section{INTRODUCCIÓN}

Un evento mítico fundante de la tradición boxística argentina fue la pelea que protagonizó Luis Ángel Firpo contra Jack Dempsey, que se realizó el 14 de septiembre de 1923 en el Polo Grounds de Nueva York, Estados Unidos. El Toro Salvaje de las Pampas combatió con valentía y tiró fuera del ring al campeón de los pesos pesados, que con ayuda regresó al cuadrilátero después de 17 segundos para ganar finalmente la pelea. Ésta fue la primera transmisión radial con un fin deportivo de Argentina. Si bien el boxeo en Buenos Aires se legalizó el 3 de enero de 1924, las notas periodísticas indican que la prohibición del pugilismo no significó la ausencia del mismo en los años anteriores (Palla, 2018).

El boxeo es la disciplina que más medallas olímpicas ha ganado para el deporte nacional. Ha tenido a lo largo de su historia referentes de reconocimiento internacional. Una variada y prolífica producción de textos da cuenta de esta relevancia: desde la literatura, pasando por el cine, hasta la información de los medios de comunicación tienen como protagonistas a boxeadores reales o imaginarios, preferentemente varones debido a que la normalización del boxeo de mujeres se produjo posteriormente, en 2001. Una brecha extensa de tiempo, 77 años, separa la licencia número 1 de Firpo de la recibida por la atleta Marcela «La Tigresa» Acuña.

Un momento clave en el crecimiento del pugilismo de nivel recreativo fue la participación en 2012 de Sergio "Maravilla» Martínez en un concurso de baile del programa con más audiencia de la televisión abierta argentina. El fanatismo por Martínez se afianzó cuando el boxeador ganó la corona mundial por el peso mediano frente al mexicano Julio César Chávez júnior, el 15 de septiembre de 2012 en Estados Unidos. Durante este año, los gimnasios aumentaron hasta un 50\% la cantidad de inscriptos, especialmente de mujeres ${ }^{2}$.

El presente artículo no trata sobre las estrellas del pugilismo, sino de las personas anónimas que lo practican a diario en diferentes clubes de Buenos Aires. El objetivo es analizar la experiencia de mujeres y varones que dedican parte de su tiempo a entrenar, ya sea en calidad de actividad recreativa o disciplina competitiva. Dos aspectos centrales y relacionados ordenan este objetivo: comprender cómo se producen la enseñanza y el aprendizaje desde y con el cuerpo; y, a su vez, conocer cuáles son los significados que las alumnas y alumnos le otorgan a la sensación de dolor siendo el boxeo un deporte de contacto.

* Financiado por el proyecto UBACyT «Deporte, cuerpo y género: etnografías sobre fútbol, CrossFit, running y boxeo en la ciudad de Buenos Aires», con sede en el Instituto de Investigaciones Gino Germani, Facultad de Ciencias Sociales, Universidad de Buenos Aires.

${ }^{1}$ El investigador señala que el British Packet and Argentine News publicó la noticia de un combate celebrado entre un inglés y un estadounidense en un barrio de Buenos Aires en el ańo 1829. Para profundizar en la discusión sobre los pormenores del boxeo en clave histórica entre 1920-1960, ver el texto del autor (Palla, 2018).

2 https://www.ambito.com/furor-maravilla-hay-boom-clases-boxeo-n3755164. Consultada el 22 de mayo de 2019. 
Los datos surgen de un trabajo de campo realizado en dos gimnasios de Buenos Aires durante distintos períodos de tiempo: una primera incursión, que se realizó entre abril de 2016 y diciembre de 2017 en el Club Atlético Chacarita, con una baja frecuencia de asistencia durante el primer ańo, que se fue incrementando posteriormente, y una segunda incursión, que comenzó en agosto de 2018 y continúa hasta el momento. La metodología es la etnografía con sus dos técnicas centrales: la observación participante y la entrevista.

Salvo excepciones (Archetti, 2001, Palla, 2018), la escasez de escritos académicos nacionales sobre boxeo es notoria ${ }^{3}$. Las producciones académicas de las Ciencias Sociales y Humanidades se han centrado principalmente en el fútbol, que es el deporte con mayor convocatoria del país. Por eso, este artículo pretende contribuir a la discusión de dicho campo de estudio.

\section{BOXEANDO}

El boxeo como espectáculo provoca posturas encontradas. Por un lado, la mirada de los detractores, que lo equipara a una práctica violenta, desconociendo su condición deportiva y acentuando las secuelas que deja con el paso del tiempo (principalmente se hace mención de las consecuencias neurológicas). Cuando la perspectiva es ajena, la escena de dos personas en un cuadrilátero batiéndose a duelo con los puños reenvía a un choque sangriento y sin sentido. Por otro lado, los aficionados del pugilismo resaltan sus virtudes para connotarlo a una manifestación artística. El encuentro físico, táctico y estratégico, entre dos deportistas se asemeja a una danza que provoca el goce estético de los espectadores.

Cuando comencé a elaborar las primeras preguntas sobre boxeo, la impresión que tenía en ese entonces era cercana a la posición crítica. Mi margen de interpretación era estrecho. La escena de dos personas enfrentándose bajo una lluvia de puños me conmovía sobremanera. Como estudiante de posgrado de antropología, había leído la etnografía de Wacquant (2006), que relata en primera persona su experiencia durante tres ańos como alumno de un gimnasio de box, ubicado en un gueto negro en la ciudad de Chicago, en Estados Unidos. Sumida en el desconcierto, pero al mismo tiempo inspirada por la lectura de Wacquant, decidí aprender en qué consistía boxear. Sin saber nada de la disciplina, atravesada por un cúmulo de sensaciones y emociones, me inscribí en abril de 2016 en un gimnasio que funciona en el primer piso del Club Chacarita, invitada por otra antropóloga que practicaba allí. Experimenté un período de adaptación durante el cual no podía superar mi vergüenza e inseguridad antes las palabras y miradas del profesor, que era sumamente exigente.

3 Actualmente, Diego Zanetti y Santiago Androulo están llevando a cabo sus investigaciones sobre boxeo para escribir sus respectivas tesis de posgrado. 
La etnografía conlleva una triple acepción: es enfoque, método y texto (Guber, 2014). Con miras a lograr el enfoque, que «constituye una concepción y práctica de conocimiento que busca comprender los fenómenos sociales desde la perspectiva de sus miembros» (Guber, 2014: 16), se desarrolla una metodología «en un terreno donde caben las encuestas, las técnicas no directivas -fundamentalmente, la observación participante y las entrevistas no dirigidas- y la residencia prolongada con los sujetos de estudios [...] cuyo resultado se emplea como evidencia para la descripción» (Guber, 2014: 19); descripción o interpretación que puede aparecer en una presentación audiovisual o escrita. Durante el trabajo de campo etnográfico, el principal instrumento de conocimiento es el investigador, que «está allí» para comprender los significados de la rutina diaria y los eventos extraordinarios de los individuos con los que interactúa. Así, frente a la incógnita que me generaba un mundo social desconocido, tomé la decisión de comprender el boxeo poniendo mi propio cuerpo. El hecho de incorporarme como alumna en un gimnasio fue delineando un conjunto de preguntas que no me había formulado con anterioridad. ¿Cómo aprendo boxeo?, ¿cuáles son los movimientos propios de esta disciplina?, ¿podré aprender un deporte que me resulta totalmente ajeno?, ¿el estilo del profesor es el de otros gimnasios?, ¿uso el cuerpo y la mente en el aprendizaje?, ¿qué rol juegan los sentidos en este proceso?

El boxeo enfrenta a dos contrincantes de un mismo sexo e igual categoría -definida por el peso corporal- que compiten en un ring por medio de golpes de puño dirigidos al cuerpo desde la cintura hacia arriba. En el profesionalismo, esto sucede para dejar fuera de combate o noquear al rival, es decir: dejarlo sin conocimiento o sin la posibilidad de seguir peleando. No es sólo un deporte de ataque, pues combina una prodigiosa defensa basada en movimientos rápidos de cintura y pies. Boxear no es sólo mostrar fuerza, potencia y resistencia, sino también desplegar flexibilidad, coordinación y fluidez. Todo esto da como resultado una expresión corporal compleja.

Existen diferentes maneras de practicar boxeo, desde el nivel recreativo, que incluye a practicantes que desean acercarse al deporte para conocer los lineamientos generales motivados por razones diversas, pasando por los que realizan un entrenamiento regular y de mayor exigencia porque intervienen en competencias amateurs, hasta los atletas del pugilismo profesional, que cobran una bolsa por pelea, cuyo plan de entrenamiento es de alto rendimiento. Si bien hay una línea de continuidad entre los niveles, pues responden a las etapas que son transitadas para llegar al profesionalismo a lo largo del tiempo, es notoria la distancia entre ellos. Por ejemplo, los boxeadores amateurs, cuyos cuerpos delgados y fibrosos denotan dos o tres horas de entrenamiento diarias durante toda la semana, que tienen movimientos técnicos precisos, y se desplazan con plasticidad fuera y dentro del ring, usan cabezal y guantes más grandes en los combates. En esta categoría, la pelea dura tres rounds de tres minutos cada uno. Ellos suelen decir: «El profesional es otra cosa», ya que los combates de esta clase pueden ir desde los nueve hasta los doce asaltos. Otra característica de este nivel es que los guantes, al ser más pequeños, y los vendajes que cubren las manos debajo de éstos más duros, provocan daños visibles en el rostro ajeno (hinchazón, cortes sobre pómulos y cejas, 
hematomas). En este último caso, las heridas contribuyen al aumento de la espectacularidad si la pelea es televisada.

Las variantes del boxeo determinan modalidades distintas de combatir y acondicionar el cuerpo, esto último está definido por el tiempo de dedicación, la intensidad, la exigencia, la alimentación, entre otras variables centrales. Según Wacquant, la ética del sacrificio del boxeador profesional engloba, además del entrenamiento, una lista de restricciones para ordenar diversos aspectos de su vida: la prohibición de comida chatarra, la vida social y las relaciones sexuales previas a un combate (Wacquant, 2006). Si bien el presente trabajo no se centra especialmente en el boxeo rentado ni en el ascetismo que signa la cotidianidad de un púgil de alto rendimiento, algunas de las facetas nombradas resultan estructurantes para el rendimiento de las personas que practican este deporte en los otros niveles. Así, un alumno que entrena cuatro veces por semana en Almagro, teniendo cinco años de experiencia allí más otros cuatro en deportes de contacto, que no tiene licencia $a m a-$ teur ni compite, comentó al final de una clase que la alimentación es un elemento esencial: "Como proteínas, pollo, pescado, palta. Si no comés bien, no subas». Él con otros compañeros suele subir al ring para realizar "guanteo», que es un ejercicio que simula un combate real debido a los desplazamientos, las "combinaciones» $\mathrm{y}$ «la defensa» de los golpes.

La clase de nivel recreativo dura dos horas y está organizada por tramos. En Almagro, por ejemplo, las alumnas y alumnos realizan un precalentamiento del cuerpo con saltos de soga, que luego continúan con «sombra» frente al espejo para dominar «la parada» de combate con pasos hacia adelante, atrás y laterales que combinan con «las manos» $\mathrm{o}$ «golpes» (jab, cross, gancho). En el paso siguiente se colocan los guantes para practicar con un elemento: "plano», «bolsa» o "cubierta», que sirven para afianzar los golpes. Después, la mayoría de los asistentes realizan «escuela», donde dos compañeros se enfrentan para hacer movimientos de «defensa». La división de la rutina en el gimnasio se organiza en base a la división temporal de una contienda real. Los ejercicios se realizan durante tres minutos, que es el tiempo que dura un asalto, seguido por un minuto de descanso. Esto es, una alumna puede hacer tres rounds de salto de soga, continuar con dos de sombra, ir a la bolsa y pasar por los otros dos elementos, a los que les dedica otros asaltos, y después continuar con los ejercicios de defensa bajo las órdenes del profesor o profesora. Cada persona está concentrada en su rendimiento, atenta a la respiración, la posición de los pies, la altura de los brazos, la colocación de los puños. El trabajo cronometrado es arduo y no deja lugar a distracciones y conversaciones. Cuando éstas se producen, son pasajeras. El boxeo es un deporte que requiere, de acuerdo a los espacios donde éste se realice, de técnica y precisión. Otra división que se produce en el entrenamiento es en base a la trayectoria. Los experimentados, con más años en el gimnasio, suben al ring, donde el entrenamiento es más exigente e intenso ${ }^{4}$.

\footnotetext{
${ }^{4} \mathrm{La}$ estructura de la clase puede ser distinta. En Chacarita, la gimnasia se realiza al inicio como precalentamiento y no al final, como en Almagro. Ésta consiste en 30 minutos (aproxima-
} 
Un aspecto distintivo del boxeo es que, si bien es un deporte individual, su entrenamiento es colectivo. El profesor de Chacarita decía durante su clase: «Cada uno perfecciona su técnica», "corrige cuando se equivoca». El entrenamiento tiene una dinámica de conjunto, que genera momentos de cooperación, intercambio y solidaridad. La ayuda de los compañeros es central en este proceso, no sólo porque los más experimentados corrigen las posturas de los novatos, aunque se respeta claramente la posición del profesor, sino también porque cuando - por ejemplo- hay contacto físico en ejercicios de ataque y defensa, los integrantes de la dupla deben medir su fuerza para no lastimar al compañero. Cuando el profesor dice «hablen con el compañero», lo hace porque el que defiende debe estar atento a la combinación de golpes del que ataca. Si uno «tira una combinación» determinada, el otro debe procurar una defensa apropiada para contrarrestar los golpes.

\section{APRENDIENDO}

Las preguntas que fui formulando durante los primeros meses en el gimnasio de Chacarita giraron en torno a ¿cómo se produce la incorporación de la técnica del boxeo (movimientos y gestos deportivos específicos de la disciplina)?, ¿con qué recursos voy a aprender los gestos y los movimientos del pugilismo?, ¿seré capaz de aprender?

Aprender boxeo poniendo el cuerpo es un proceso constante, que no finaliza, porque siempre hay gestos para perfeccionar. Especialmente durante las clases en Chacarita, dirigidas por un profesor que en ese entonces era integrante del cuerpo técnico del seleccionado olímpico femenino, se intercalaban o combinaban la explicación con el cuerpo físico y la palabra hablada. En lo personal, aprendía mirando y escuchando al entrenador. Miraba, escuchaba, copiaba e imitaba sus movimientos. Por momentos, la explicación de los otros y/o mi mirada se detenían en una parte del cuerpo, que en ese instante se transformaba en un cuerpo en disección. La parada de combate es central en el boxeo («se empieza de abajo hacia arriba», decía el profesor), por eso miraba el ancho y posición de mis pies, probaba la flexibilidad de las rodillas, rotaba apenas la cadera para lanzar luego el brazo en dirección de ataque. Por instantes, en silencio, de manera introspectiva, sin palabras en voz alta, ensayaba recordando y analizando las imágenes que me habían quedado de la explicación gestual y/o verbal. Incluso, seguía pensando y recordando después de la clase. Ese proceso mental estaba atravesado por recuerdos y olvidos. Trataba de memorizar las sugerencias para no redundar en errores corregidos una y otra vez por el entrenador: mantener la guardia alta, no anticipar el golpe, sacar las manos desde

damente) de saltos en el lugar con movimientos de brazos, piernas y cintura. Otra diferencia entre gimnasios es que en Chacarita el entrenamiento se estructura en base a la incorporación de la técnica, como veremos más adelante bajo el paradigma de la "vieja escuela», y en el paso por más estaciones para entrenar con más elementos (trabajo de cintura, punching ball, neumáticos en el piso). 
el mentón, girar el talón. En clase, corregía y, en ese devenir, sucedían otros descuidos (me olvidaba, por ejemplo, de acompañar los movimientos con la respiración).

La enseñanza y el aprendizaje del boxeo mixturan la razón, la cognición, el análisis y las experiencias corporales a través de los sentidos. El cuerpo y la mente se entremezclan en la clase: la palabra y el movimiento, la verbalización y la motricidad, son estructurantes de esta instancia. Siguiendo a Carozzi (2011), intento "problematizar la división entre mentes que hablan y cuerpos que se mueven [...]». Esto es «prestar atención, intencional y conscientemente, a la relación entre palabra y movimiento» (2011: 33) en la incorporación de las técnicas corporales del boxeo. ¿Qué están haciendo (pensando, conceptualizando) las personas, desde su punto de vista, cuando a nuestros ojos aparecen bailando?, pregunta Carozzi en su investigación sobre tango. La cuestión es interesante para no desdeñar la oportunidad de comprender el papel que juega la mente, la cognición, la palabra en la comprensión y naturalización de la disciplina deportiva.

$\mathrm{Al}$ respecto, Bourdieu sugiere un punto discordante:

Pienso que el deporte es, junto con la danza, uno de los terrenos donde se plantea con la máxima agudeza el problema de las relaciones entre la teoría y la práctica, y también entre el lenguaje y el cuerpo [...]. Existen cantidades de cosas que comprendemos solamente con nuestro cuerpo, más acá de la conciencia, sin tener las palabras para decirlo [...] hay cosas que no se saben decir, y las prácticas deportivas son esas prácticas en las cuales la comprensión es corporal. Muy a menudo no se puede más que decir, «Mira, haz como yo» (Bourdieu, 1987: 182).

Es cierto que después de un período de práctica insistente se produce $-\mathrm{o}$ no se produce- la incorporación del gesto deportivo. Esto se manifiesta cuando el movimiento ya no se piensa y resulta natural. Así, «sólo la experimentación carnal permanente que supone el entrenamiento como complejo coherente de "prácticas de incorporación" permite adquirir este control práctico de las reglas del pugilismo que, justamente, dispensa de constituirlas como tales en la conciencia» (Wacquant, 2006: 75). En términos de Bourdieu, se produce una incorporación de disposiciones duraderas que ya no pasan por la conciencia.

Estudiar, comprender, interpretar antropológicamente una práctica corporal plantea el problema de la traducción. Cómo producir una "descripción densa» (Geertz), respetando los marcos de interpretación del grupo social con el que interactuamos cuando la práctica cultural investigada es corporal. Wacquant, siguiendo a Bourdieu, cuestiona:

¿Cómo dar cuenta antropológicamente de una práctica tan intensamente corporal, de una cultura tan profundamente cinética, de un universo en el que lo más esencial se transmite, se adquiere y se despliega más allá del lenguaje y de la conciencia; resumiendo, de una institución hecha hombre que se sitúa en los límites prácticos y teóricos de lo habitual? (Wacquant, 2006: 19).

A partir de la experiencia de entrenamiento en dos gimnasios de boxeo, traducir con palabras los movimientos corporales, estar más acá o más allá de un estado 
de conciencia plena, comprender con el cuerpo sin usar palabras dependerán de la noción que el lugar tenga sobre «enseñar boxeo».

Marcel Mauss (1979) sostuvo que cualquier técnica corporal -caminar, correr o comer- siempre está imbricada dentro de la cultura de un grupo social donde surge y a partir de la cual cobra sentido. Dicho de otro modo: las maneras de caminar o de correr son diferentes de acuerdo a cada cultura, porque no existe una técnica corporal del correr que sea universal.

La danza no es una categoría universal. Ésta adquiere significados distintos de acuerdo a los contextos culturales particulares (no es lo mismo la danza occidental que la danza en una comunidad aborigen, hay similitudes y diferencias) (Carozzi, 2011). El boxeo no es ajeno a los usos y la conformación de estilos diversos. Es un deporte occidental con reglas que están definidas por las asociaciones que nuclean a los deportistas ${ }^{5}$. No obstante, más allá de las reglas que institucionalizan la disciplina, existen escuelas con maneras singulares de enseñar e impartir boxeo.

En una conversación que sostuve con un alumno del nivel competitivo del gimnasio de Almagro, con licencia amateur, surgió el tema de mi entrenamiento en el gimnasio anterior. Mis comentarios se dirigían a decir que el profesor era «exigente", que el lugar se caracterizaba por la disciplina, que pocos osaban hablar a viva voz, que el entrenamiento era "muy técnico", pues buscaba la perfección. También hablé sobre la insistencia del profesor de aprender un ejercicio para poder pasar al siguiente escalón. Para «agregar» algo nuevo debía aprender lo anterior. Así, por ejemplo, transcurrieron varias clases en las que estuve frente al espejo practicando cómo "pararme» ${ }^{6}$. Después de aprender a pararme y balancearme como una surfista imaginaria sobre mis pies (sintiéndome por momentos ridícula), en la séptima clase el profesor dijo "la mano al mentón». En rigor, debía llevar las dos manos hacia la cara para completar «la parada» de combate. En la clase siguiente, recién llegó la primera «mano», el primer lanzamiento del brazo derecho. El objetivo era aprender con la mayor precisión posible el gesto corporal para «no trasladar el error». Lo cierto es que cuando alguien se equivocaba de manera persistente llegaba la advertencia del profesor: "Vas a volver al espejo», "te voy a sacar las vendas», que implicaba retroceder momentáneamente en el proceso de enseñanza. Éstas son algunas de las facetas de lo que se llama «la vieja escuela». En palabras de mi compañero de Almagro:

$\mathrm{X}$ en la nueva escuela no te tiene caminando 3 meses hasta que sale perfecto sino que son unos rounds y después ya empezás a tirar golpes rectos y de ahí a la bolsa

5 Asociación Mundial de Boxeo (AMB), Consejo Mundial de Boxeo (CMB), Federación Internacional de Boxeo (FIB), Organización Mundial de Boxeo (OMB).

${ }^{6}$ Las piernas ubicadas según ancho de hombros. La pierna izquierda adelantada con todo el pie apoyado. La pierna derecha se deja atrás, apoyando la parte anterior del pie y separando el talón del piso de tres a cinco centímetros. Si la persona es zurda, tiene que cambiar el perfil o «la guardia».

7 Sólo para dar otro ejemplo, un profesor me habló de la escuela rusa y la escuela cubana. Ésta última con más ascendencia entre las boxeadoras y boxeadores argentinos; y de las diferencias en torno a la enseñanza de la técnica. 
[...]. Y en vez de esperar que en la sombra salga perfecto se hace en la bolsa y de última se corrige en ese lugar. Y de esa forma no es tan aburrido [...]. Sí, en la vieja escuela no pasas a otro ejercicio si no aprendes lo anterior. Podés estar hasta un año (risas), depende de la capacidad motriz y del aprendizaje de cada uno.

El turno al que voy en Almagro tiene otra filosofía. Me sorprendí cuando el primer día la profesora a cargo de la clase dijo: «Las vendas y los guantes». No había llevado dichos elementos para esa clase. El estilo de enseńanza es relajado, al punto que las alumnas y alumnos practicamos dos horas de entrenamiento con pocas intervenciones y correcciones de los entrenadores.

Por su parte, las clases en Chacarita estaban plagadas de miradas y correcciones, algunas bastante severas, por parte del entrenador. El profesor usaba metáforas para explicar los movimientos y también informaba el motivo de la práctica de ciertos ejercicios («un buen ejercicio de cintura es una buena defensa en el futuro», «este ejercicio es para tapar la cara», éste otro "para esquivar». Así, se observa que «las palabras con las que se designa el movimiento aparecen aquí íntimamente ligadas con los modos en que éste se enseña, se aprende y se ejecuta» (Carozzi, 2011: 9).

Como el aprendizaje no es homogéneo porque depende de las capacidades individuales y de la incorporación subjetiva de los estilos de las escuelas, las maneras de boxear tienden a multiplicarse. Es interesante mencionar que los y las atletas hacen uso de la batería de gestos, técnicas, movimientos que han incorporado a lo largo de los años de entrenamiento, y dependerá de cada uno cómo hace uso del «capital corporal» (Wacquant, 2006).

\section{SINTIENDO (DOLOR)}

¿Cuáles son las experiencias sensoriales (dolor, placer) durante el entrenamiento y el combate? ¿Qué significados le atribuyen los y las boxeadoras al dolor? Más allá de la definición médica que señala una sensación de displacer debido a un daño tisular ${ }^{8}$, existen diferentes maneras de experimentar y comprender el dolor en el gimnasio.

Durante las dos horas de entrenamiento en Almagro, las sogas repiquetean en el suelo de goma -algo deteriorado por el tránsito constante y el trabajo duro, que no cesa-, la música acompaña los ejercicios como un telón de fondo, las indicaciones del profesor guían la dinámica de los alumnos, las exhalaciones fluyen en coordinación con los movimientos, los pasos de dos contrincantes resuenan en el ring, los golpes entre guantes y contra las bolsas y demás elementos del gimnasio dominan por momentos la sonoridad del gimnasio. Al conjunto de sonidos se unen

${ }^{8}$ La Asociación Internacional para el Estudio del Dolor definió el dolor como «una experiencia sensorial o emocional desagradable asociada a un daño real o potencial en un tejido, o descrito en términos de dicho daño». https://www.grunenthal.org/grt-change-pain-portal/change_pain_ home/chronic_pain/insight/definition/es_ES/324800317.jsp. Consultado el 24 de mayo de 2019. 
los quejidos que surgen espontáneamente durante o en el instante final de un ejercicio. Es común que éstos se expresen con más libertad durante la sesión de abdominales que se realiza después de saltar y mover los brazos por media hora al compás de la gimnasia. La cantidad de abdominales, de distinta dificultad, llega a 250 por clase. Es la fase del entrenamiento en la que los alumnos y alumnas ponen la última cuota de energía. Por eso se extienden y agudizan los gemidos, alaridos, exhalaciones bruscas que se dan en simultáneo con gestos de dolor. Experimenté la sensación que había escuchado de un compañero durante la gimnasia: "Me quema», a raíz de un ejercicio en el que debía mantener los brazos a la altura de los hombros por varios segundos («mantengo, mantengo, mantengo», dice el profesor) para llevarlos hacia arriba por otros varios segundos, haciendo tres o cuatro repeticiones según la indicación del entrenador. "Me quema» puede traducirse como "me duele», «no aguanto más». No obstante, es interesante notar que tales sensaciones de incomodidad y sufrimiento son procesadas como experiencias gratificantes que generan bienestar. Un compańero durante una sesión de sombra frente al espejo me dijo: el entrenamiento es «dolor con endorfinas».

Por otra parte, especialmente para los novatos, el dolor funciona como el descubrimiento de los músculos que no habían notado con anterioridad. Una fotógrafa aficionada y practicante de boxeo contó en una entrevista para un medio gráfico:

Toda mi vida hice deporte: gimnasia artística hasta los quince, entrenaba cinco horas diarias. También hice básquet federada, jugué al fútbol [...]. Pero el boxeo es distinto a todos. Cuando empecé a entrenar me dolía hasta la oreja, incluso descubrí músculos que nunca había entrenado (Sullivan, n. ${ }^{\circ}$ 9, junio de 2017).

En este sentido, existe una dimensión pedagógica del dolor (Rodríguez, 2017), que indica que el cuerpo ha hecho un esfuerzo considerable y que se está acondicionando físicamente. El dolor muscular sin lesión es un indicador del proceder correcto y progresivo de los ejercicios y del entrenamiento. El músculo «quema» y esto es una señal de que el cuerpo se está fortaleciendo.

... el dolor no es mera negatividad sino que tiene un sustrato positivo. Los entrenados descubrieron, a medida que avanzaron en su experiencia, que una recompensa los esperaba al final del camino. Esa recompensa, producto del sacrificio al que se sometieron, es un cuerpo renovado pero también una manera de verse y pensarse a sí mismos totalmente distinta a la que poseían cuando llegaron al gimnasio (Rodríguez, 2017: 752).

Los alumnos con más experiencia del nivel recreativo incorporan nuevos sentidos del dolor. Así, en una conversación informal, uno de ellos, frente a mi pregunta sobre cómo hacía con el dolor de los golpes recibidos en el cuerpo, contó:

9 Son aquéllos que no compiten, pero tienen una experiencia de varios ańos en Almagro. Asisten entre cuatro o cinco veces por semana y son los que suben al ring para hacer trabajos más avanzados. 
... la gimnasia ayuda. Cuando vos sentís, decís «este ejercicio no me sale» es el que tenés que hacer. La gimnasia (del final de la clase) ayuda porque te permite estar más suelto... dolor, dolor... No sé si sentís arriba. Porque aprendés a absorber el golpe. Si estás abarrotado (rígido, duro), te va a doler. Si estás blando y te pegan y te movés (hizo el gesto que el cuerpo se movía al compás del golpe del otro, abajo a la altura del hígado), no te duele tanto. Más te duele en el entrenamiento.

«Absorber» es un término que había escuchado en otras ocasiones en el mundo del boxeo. Pensé que refería a «acostumbrarse» a los golpes, pero Mariano le dio otro significado: el cuerpo debe estar flexible y atento, con «reflejos», para esquivar un golpe pleno del otro. Explicó que la gimnasia le daba soltura para realizar un gesto de defensa y no quedar demasiado expuesto. «Vos me tirás una piña a mí en la cara... hay que tener reflejos» para dar, por ejemplo, un paso atrás.

En el mismo sentido se expresó Alexis, que participa en exhibiciones y competencias, que tiene licencia de boxeador amateur.

Tengo un umbral del dolor bastante amplio, así que casi... por lo general rara vez siento mucho mucho dolor. Creo que nunca sentí «dije dejo esto porque duele mucho o algo así». El peor dolor es el de las lesiones. Ya sea que en una pelea te disloques un dedo, o un desgarro o algo así. Pero más allá del dolor físico es un dolor psicológico porque sabés que vas a tener que parar. Y después, en medio de una pelea, cuando me pegan y siento una piña me hace salir más adelante, y buscar con más fervor una pelea.

En el profesionalismo, los comentarios son distintos. En una conversación, la boxeadora profesional y entrenadora del gimnasio del turno recreativo asumió que «los golpes siempre duelen», pero lo importante cuando estás en el ring es no demostrar con el rostro que «la pińa duele». Esta actuación debe estar dirigida no sólo al rival, sino también al público y los jueces. Smith propone, en el mismo sentido, que «en el universo de la lucha profesional, prevalece el estoicismo frente al dolor, a pesar de la gran necesidad que tienen los luchadores de expresar sus emociones. Los participantes no deben expresar ningún sufrimiento ni vulnerabilidad proveniente de una sensación de dolor» (Smith, 2011: 133).

Por su parte, la investigadora Veena Das expresa:

Si observamos los contextos normales en los cuales, por ejemplo, se le obliga al neófito a someterse a dolorosas mutilaciones del cuerpo, como ocurre en los rituales de iniciación de diversas sociedades, podemos terminar considerando el dolor no como una forma somatizada de crítica social, sino como el medio a través del cual la sociedad integra a sus miembros en una única comunidad moral (Das, 2008: 413).

La noción de integrar a los miembros en una comunidad moral es potente si partimos de la noción del boxeo como un deporte individual, en el que los puños se usan para noquear o dejar fuera de competencia al rival. Más allá de la comunidad moral que podría conformarse con las boxeadoras y los boxeadores de otros gimnasios, un aspecto que aún debo indagar, es pertinente señalar que los alumnos de los distintos niveles de Almagro hablaron de «la camaradería», la constitu- 
ción de una «familia», el «respeto» y la enseñanza de «los valores» que circulan allí. Magela, una alumna de nivel competitivo, comentó: «La gente se respeta [...] cuando subo no tengo ganas de lastimar a nadie, no subo con odio. El profesor me enseñó a boxear, el respeto y los valores». Así, "protegerse entre sí contra el dolor o las lesiones presenta una forma latente de conexión social» (Smith, 2011: 136). El gimnasio se conforma como un espacio con códigos propios, que permite momentáneamente el alejamiento de la cotidianidad. Para Wacquant, «el gym es, además, una escuela de moralidad en el sentido de Durkheim, es decir, una máquina de fabricar el espíritu de la disciplina, la vinculación al grupo, el respeto tanto por los demás como por uno mismo y la autonomía de la voluntad, aspectos indispensables para el desarrollo de la vocación pugilística» (Wacquant, 2006: 30).

En la misma línea, el aspecto vincular se observa cuando las personas hablan de las veladas de boxeo (la organización de una serie de peleas de distintas categorías en las que compiten varios gimnasios). Ellas cuentan que el público es «familiar» no sólo porque asisten los familiares de las boxeadoras y boxeadores que suben al ring, sino también porque «lo familiar» refiere a los asistentes asiduos y amantes del boxeo.

\section{CONCLUSIÓN}

Ingresar al mundo del boxeo como alumna me ha permitido durante estos largos meses conocer los significados nativos que rondan la práctica. Desde aquellos primeros días, cuando me acerqué siendo completamente ajena a este ámbito, hasta hoy, fui desarmando el cúmulo de prejuicios y estereotipos que tenía. Convertí la mirada externa, que sólo veía sobre el ring a dos personas enfrentándose sin lógica, en una mirada con múltiples profundidades y matices. Logré el objetivo de desactivar la idea del boxeo como un deporte violento para bestias. Aprendí con el tiempo la diferencia entre pelear y boxear. Aprendí que el boxeo se define de diversas formas, pero que lo esencial es saber que es un deporte de contacto con un conjunto de técnicas y tácticas de ataque y defensa. Que todo esto da como resultado un espectáculo para mirar. Observar y participar como alumna en Chacarita y Almagro me ha facilitado conocer desde adentro los pormenores de los entrenamientos, brindándome esto además los recursos para comprender de mejor manera este deporte. Un planteo asociado a un trabajo de campo con enfoque etnográfico es ¿cómo hacemos las investigadoras/es para traducir aquello que observamos, escuchamos y registramos, máxime si lo que estudiamos es una práctica corporal? Intervenir como alumna en los gimnasios me ha permitido canalizar esta traducción pasando por el propio cuerpo las múltiples enseńanzas y sensaciones. Esto, de ningún modo, quiere decir que la estrategia de investigación sobre el boxeo se supedite únicamente a desarrollar la práctica.

El artículo muestra que mente y cuerpo, verbalización y motricidad, ambos en relación, son centrales en el proceso de encarnación del saber pugilístico. Que los procesos mentales y corporales a través de los sentidos se imbrican para dar sentido a lo que se está haciendo y está transcurriendo. Que la insistencia en el aprendizaje puede llevar a la naturalización del gesto deportivo o, por el contrario, no produ- 
cirse la encarnación. Por otro lado, pese a la existencia de reglas del boxeo puestas de manifiesto por las asociaciones y federaciones, los profesores/as al mando del gimnasio dan su impronta a las clases, generando así maneras diferentes de enseñar, y también de aprender. Más allá de las diferencias entre los gimnasios donde he transitado, el proceso de enseńanza-aprendizaje se realiza bajo un régimen de entrenamiento intenso en el que el cuerpo es el principal objeto para modelar. El gimnasio es un espacio donde el trabajo es disciplinado, ordenado y metódico. Si bien hay distancias entre los niveles de aprendizaje (recreativo, amateur, profesional), ciertos hábitos saludables condicionan favorablemente el rendimiento físico.

Buscar los significados del dolor en un deporte de combate ha sido un objetivo del trabajo. El dolor de una lesión, que no fue profundamente tratado aquí, pero que algunos alumnos mencionan como una sensación claramente negativa, se suma a otros sentidos. Así, ciertos alumnos dieron cuenta del dolor placentero, que está unido a la generación de endorfinas durante y después de un entrenamiento de dos horas. Un entrenamiento durante el cual los alumnos y alumnas experimentan la sensación de "no aguantar más», de estar exhaustos, sin carga de energía. Es el dolor pedagógico que indica que están en el camino correcto.

Resulta interesante retomar los dichos de Veena Das en términos de cómo el dolor puede funcionar como un medio para integrar en una comunidad moral a los miembros de una sociedad. El boxeo es un deporte individual que se practica de manera colectiva. Éste no es un dato menor, puesto que los integrantes de una dupla trabajan en combinación en base al apoyo mutuo y la solidaridad.

Finalmente, esta comunidad moral aleja de las dificultades del día a día. Frente a la angustia generalizada producida por las medidas económicas de turno, que no cesan de eliminar los derechos adquiridos de las ciudadanas y ciudadanos del país, el gimnasio ofrece un lugar donde las presiones se desvanecen. Lo que queda son las personas entrenando y luchando por una superación individual y colectiva. Hoy, un muchacho del gimnasio me dijo: «No hay trabajo, vengo a boxear». 


\section{REFERENCIAS BIBLIOGRÁFICAS}

ArChetTi, Eduardo (2001). El potrero, la pista y el ring. Las patrias del deporte argentino. Buenos Aires: Fondo de Cultura Económica.

Bourdieu, Pierre (1987). Cosas Dichas. Buenos Aires: Gedisa.

Carozzi, María Julia (2011). «Introducción», en M.J. Carozzi (ed.), Las palabras y los pasos: etnografías de la danza en la ciudad. Buenos Aires: Gorla.

DAs, Veena (2008). Sujetos del dolor, agentes de dignidad. Bogotá: Pontificia Universidad Javeriana, Universidad Nacional de Colombia Sede Medellín, Sede Bogotá Facultad de Ciencias Humanas Centro de Estudios Sociales-CES.

Geertz, Clifford (1988). La interpretación de las culturas. Barcelona: Gedisa.

Guber, Rosana (2014). La etnografía. Método, campo y reflexividad. Buenos Aires: Siglo XXI.

Mauss, Marcel (1979). Sociología y antropología. Madrid: Tecnos.

Palla, Jonathan (2018). «Bitácora de Willie Farrell. Pugilismo, escenarios y negocios a ambos lados del Atlántico. (1920-1960)». Claves. Revista de Historia, vol. 4, n. ${ }^{\circ} 7$ Montevideo: 57-86.

Rodríguez, Alejandro (2017). «Si te duele es porque estás entrenando bien. La sensación paradójica de dolor corporal en los gimnasios de fitness de la ciudad autónoma de Buenos Aires». Movimento, v. 23, n. ${ }^{\circ}$ 2. Porto Alegre: 743-754.

Sмiтh, Tyson (2011). «El dolor en la acción: los significados del dolor que experimentan los luchadores profesionales», en J. Javier Auyero y R. Hobert. Acción e interpretación en la sociología cualitativa norteamericana. La Plata: EPC, Universidad Nacional de La Plata; Ecuador: Flacso. Sullivan, n. ${ }^{\circ}$ 9, junio de 2017.

WacQuant, Loic (2006). Entre las cuerdas: cuadernos de un aprendiz de boxeador. Buenos Aires: Siglo XXI. 